Profesora en Lengua Castellana y Comunicación, Licenciada en Educación por la Universidad Arturo Prat; Diplomada en Literatura y Pensamiento Femenino Latinoamericano por la Pontificia Universidad Católica de Valparaíso; Tallerista en Perspectiva de Género por Ímpetu Centro de Estudios A.C, México. Sus intereses temáticos son la producción literaria y poética femenina latinoamericana y estudios de género.

Historial editorial Recepción: 11 de marzo de 2021

Revisión: 19 de marzo de 2021 Aceptación: 23 de mayo de 2021 Publicación: 28 de junio de 2021 


\title{
Gabriela Mistral y su transgresión poética
}

\section{Gabriela Mistral and her poetic transgression}

\section{Gabriela Mistral e sua transgressão poética}

\author{
Helena M. Garrido \\ Pontificia Universidad Católica de Valparaíso \\ belenantonieta@gmail.com
}

\section{Resumen}

A Gabriela Mistral se le ha leído en clave maternal por la preocupación que tuvo por la infancia y por los poemas dedicados a ella, dejando de lado su poética rebelde y subversiva para así perpetuar esta imagen en la ganadora del Nobel (1945) manteniendo así el orden simbólico patriarcal. En este ensayo se revela que la poesía de Gabriela Mistral tiene un trasfondo político, subversivo, feminista y lesbiano que la crítica patriarcal encubrió con la figura materna constituyendo así el rol social que se le asigna a la mujer.

Palabras clave: Feminismo, Patriarcado, Maternidad, Locura mistraliana, Literatura 


\begin{abstract}
Gabriela Mistral has been read in a maternal key because of the concern she had for childhood and for the poems dedicated to her, leaving aside her rebellious and subversive poetics in order to perpetuate this image in the Nobel winner (1945), thus maintaining the patriarchal symbolic order . In this essay it is revealed that Gabriela Mistral's poetry has a political, subversive, feminist and lesbian background that patriarchal criticism concealed with the maternal figure, thus constituting the social role assigned to women.
\end{abstract}

Keywords: Feminism, Patriarchy, Motherhood, Mistraliana Insanity, Literature

\title{
RESUMO
}

Gabriela Mistral foi lida em tom materno pela preocupação que tinha com a infância e com os poemas que lhe eram dedicados, deixando de lado sua poética rebelde e subversiva para perpetuar essa imagem no Nobel (1945), mantendo assim a ordem simbólica patriarcal. Neste ensaio é revelado que a poesia de Gabriela Mistral tem uma trajetória política, subversiva, feminista e lésbica que a crítica patriarcal escondeu com a figura materna, constituindo assim o papel social atribuído à mulher.

\section{Palavras-chave: Feminismo, Patriarcado, Maternidade, Insanidade Mistraliana, Literatura}


Bien conocida es la vida y obra de la célebre, primera y única (mujer) ganadora del Premio Nobel de Literatura en Latinoamérica, Gabriela Mistral. Su obra ha trascendido fronteras territoriales y temporales, y su imagen ha sido inspiración para las generaciones siguientes, sobre todo para agrupaciones feministas y lesbianas feministas que la han utilizado como símbolo de reivindicación femenina en la lucha por el posicionamiento de la mujer en una sociedad patriarcal. En cuanto a su obra, refleja su postura política, filosófica y rebelde donde reivindica tanto la infancia como etapa fundamental del ser humano por la que hay que velar, proteger y cuidar, y a la mujer como una figura oprimida por una sociedad machista y a la cual cobija y libera dentro de su poesía donde, además, ella misma encuentra resguardo de una sociedad conservadora. Sin embargo, el canon literario que es masculino, machista y patriarcal, utilizando la poética infantil de Gabriela Mistral, creó la imagen maternal de ella ocultando su lado subversivo, rebelde y político, puesto que "la tradición literaria envuelve las obras de mujeres, para contener y retener sus energías más transgresoras bajo el disfraz de una femineidad-tipo: una femineidad atada a una cierta ideología materna de la abnegación y del sacrificio". (Piñones 1998 135). Dicho lo anterior:

Gabriela Mistral ha sido por muchos años leída y divulgada en clave maternal. La autora de las bellas canciones de cuna, las rondas, los magníficos remakes de clásicos libros infantiles, y de sus poemas sobre la maternidad, ciertamente dieron pábulo a la creación de una imagen que interesadamente el mundo conservador chileno difundió después de su muerte, porque afirmaba a la mujer en el rol que en la época se le atribuía y le prestaba al catolicismo más vigilante una figura dotada del prestigio del Premio Nobel para contrarrestar la influencia del feminismo. (Ricardo Brodsky).

Lo anterior se refleja claramente en "Recado a Gabriela Mistral" de Marie-Lise Gazarian Gautier donde en un acróstico evoca a la Gabriela madre, a la Gabriela maestra y a la Gabriela católica, símbolo de una sociedad conservadora-patriarcal que logró establecer en el imaginario de la población chilena el perfil de abnegación maternal. De este modo, durante décadas la imagen de Gabriela Mistral no fue más que la de la madre de Chile. "Así, el cercamiento de la plenitud mistraliana, operada desde el poder, tiene que ver con una escisión de su diversidad: la clase de femineidad aceptada por esta versión oficial, ha destacado los roles más pasivos y menos rupturistas del discurso mistraliano". (Piñones Lizama 1998 136). Sin embargo, en el último tiempo se le ha reivindicado desde el feminismo (a pesar que ella misma no se reconocía como tal) por su postura crítica a las desigualdades de género y de clase de su época, que abarca la defensa de la emancipación de la mujer desde la publicación "La instrucción a la mujer" en el 
periódico La Voz del Elqui en 1906. En dicha publicación, una Gabriela Mistral joven expresa cómo el sistema patriarcal ha subordinado a la mujer castrándola de los espacios públicos y relegándola a la necesidad viril a través del matrimonio y labores del hogar; manifestado en los párrafos siguientes:

(...) Que la ilustración le haga conocer la vileza de la mujer vendida, la mujer depravada. I le fortalezca para las luchas de la vida.

Que pueda llegar a valerse por sí sola i deje de ser aquella creatura que agoniza y miseria si el padre, el esposo o el hijo no le amparen

(...) Que la gloria resplandezca en su frente i vibre su nombre en el mundo intelectual (Mistral 1906).

Estas manifestaciones a favor de la autonomía femenina continuaron dentro de su poesía y se reflejan en algunas de las secciones de sus poemarios como lo son "La Desvariadora" en Ternura (1924) y "Locas Mujeres" en Lagar (1954). En ambas, tanto el mensaje del contenido poético como el nombre de cada sección es el mismo: el delirio de mujeres que se genera a raíz de la estructura patriarcal de una sociedad machista que las constituye en un rol del que les será difícil evadir. Sin embargo, la sutil pero transgresora pluma de Mistral une a las mujeres en un mundo de locura donde se liberan del yugo patriarcal dejando en evidencia la violencia ejecutada por este sistema.

La palabra de estas mujeres brota dura y atormentada, reproduciendo el discurso alterado y tenso que se entiende como el de la locura. Confirman este discurso de la locura las varias referencias en los poemas al acto mismo de hablar, tal como lo cumplen estas mujeres locas. (Santiago Daydí-Tolson 1992 184).

De este modo, Mistral les da voz a mujeres silenciadas e intimidadas y libera sus emociones contenidas, como lo reflejan los versos siguientes en los cuales evoca a una mujer decidida y segura de sí misma, sin miedo a expresar la disconformidad de una relación dolorosa:

Me he sentado a mitad de la tierra, amor mío, a mitad de la vida, a abrir mis venas y mi pecho, a mondarme en granada viva, y a romper la caoba roja de mis huesos que te querían (1906).

Así mismo, muestra a una mujer reconociendo, aceptando y despojando la violencia a la que estuvo expuesta:

Estoy quemando lo que tuvimos:

los anchos muros, las altas vigas, descuajando una por una

las doce puertas que abrías

y cegando a golpes de hacha

el aljibe de la alegría (1906). 
De igual manera, alude a la preocupación maternal [entendida como la exageración de las madres] ante el futuro de sus hijas e hijos. En los versos continuos se observa el deseo de la madre al no querer que la hija crezca:

Yo no quiero que a mi niña

la vayan a hacer princesa.

Con zapatitos de oro, ¿cómo juega en las praderas?

Y cuando llegue la noche

a mi lado no se acuesta...

Yo no quiero que a mi niña

la vayan a hacer princesa (1906).

Hasta la actualidad, la "llegada" de la menstruación es un hecho que, socialmente se cataloga como el paso de niña a mujer. Lo que quiere decir que las niñas deben comportarse de forma distinta, a diferencia de los niños que pueden seguir actuando como tal. En relación a la estrofa anterior, existe el temor del paso abrupto niña-mujer, debido a que así como las niñas deben actuar diferentes, las madres también deben actuar diferidamente con sus hijas. Además, conocen el destino que les espera: subordinación ante una figura viril:

Y menos quiero que un día

me la vayan a hacer reina.

La subirían al trono

a donde mis pies no llegan.

Cuando viniese la noche

yo no podría mecerla...

¡Yo no quiero que a mi niña

me la vayan a hacer reina! (1906).

En tal caso, la niña convertida en mujer al contraer matrimonio se aleja aún más de la madre con un mismo destino en común: despojadas de su libertad.

Igualmente, Mistral evidencia la violencia sexual que mujeres padecen dentro de matrimonios consolidados, conservados y resguardados por su silencio y resignación.

No me alzo, no abro los ojos,

y sigo su forma entera.

Un instante, como precitos,

bajo la noche tenemos tregua;

pero le oigo bajar de nuevo

como en una marea eterna (1906).

Más aún, revela las emociones contenidas en aquel acto agresivo y carente de cuidado que sólo busca satisfacer necesidades masculinas: 


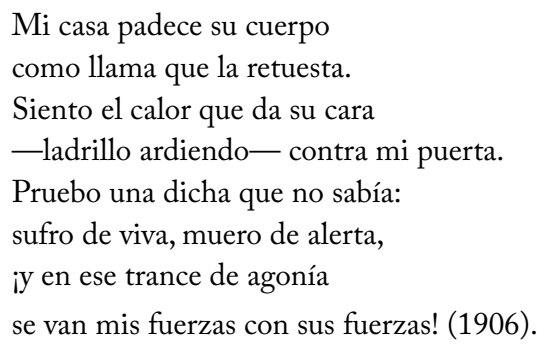

Ciertamente la locura mistraliana se basa en el acto mismo de hablar de mujeres conscientes de su situación, expresan su sentir, sus emociones y sus anhelos...porque una mujer que pronuncia, manifiesta y discute, está loca. De tal forma:

La locura no tiene en Mistral el carácter negativo de lo psicopatológico, sino todo lo contrario: es una virtud, un signo de superioridad espiritual de la mujer. Su locura, como la de sus demás mujeres, no es el resultado de un quiebre emocional, sino el efecto de una fuerza avasalladora de reacción extrema contra la realidad definida desde lo masculino. (Santiago Daydí-Tolson 1992 186)

Ciertamente la poética de Gabriela Mistral transgrede los parámetros establecidos por una sociedad machista, la cual asigna a la mujer a un rol que les resta voz y las asigna a un estereotipo de lo femenino el cual la misma Gabriela quebrantó con su presencia y actitud conflictiva [como se le ha denominado]. De acuerdo a esto, Mistral, al crear un espacio netamente femenino en su poesía conforma una comunidad entre niñas y mujeres quienes convergen en un sitio común: las rondas

Las madres, subiendo la ruta

De olores que lleva al pinar,

Llegando a la rueda se vieron

Cogidas del viento volar... (1906).

Mistral formó en las rondas un aquelarre donde se reúnen las locas y las futuras locas y, donde las libera y se libera a sí misma reflejando su yo en la locura de cada una de ellas. Es decir, "la elección de la locura como manifestación de su yo resulta en Gabriela Mistral de una voluntad de afirmarse en aquellos aspectos de lo femenino que le aseguran no tanto una superioridad como una diferencia con respecto a la sociedad manipulada desde valores masculinos" (Santiago Daydí-Tolson 1992 187).

\footnotetext{
y así erguidas o cegadas

todas una sangre misma

se nos rasga el secreto

de las sin razón venidas (1906).
} 
En consecuencia, el carácter transgresor de su obra y de su persona pusieron en jaque las representaciones de género de la época generando una censura por parte del medio, ya que "todos los aspectos de carácter inconformista mistraliano, que pudieran considerarse como conflictivos; también han quedado fuera por contradecir el modelo que ha interesado oficialmente cultivar" (Julio Piñones Lizama 1998 136). Así pues, la obra y la figura desobediente, quebrantadora y activista de Mistral se vio desplazada para abrir paso a su obra más mesurada, dócil y sensible que guarda relación con la infancia, provocando la imagen maternal de una Gabriela rebelde. Esto, en palabras de Sutherland (2016) "es una censura que está ordenándole a la gente cómo leer los textos" de la célebre y polémica Premio Nobel manteniendo así el status quo de la estructura patriarcal tanto en la producción poética como en el sistema social el cual "reserva territorios compartimentados para cada sexo: la interioridad doméstica y familiar para la mujer, la exterioridad social y política para el hombre" (Nelly Richard 1994 136). De esta forma, la identidad de Gabriela Mistral se vio fragmentada en Gabriela pública: madre de Chile y Gabriela privada: lesbiana transgresora [no hay que negar este hecho fundamental en su vida que se ha censurado hasta ahora]

Doblarse no sabía

la planta de montaña,

y al costado de ella,

yo me doblaba

La dejé que muriese,

robándole mi entraña.

Se acabó como el águila

que no es alimentada (1906).

En relación a esto, la imagen canon de Gabriela Mistral se conformó de acuerdo a las lecturas indudablemente masculinas preocupados por la sensibilidad mistraliana que tuvo por la infancia, además del interés por levantar la figura maternal a través de la poesía de Gabriela Mistral. Sin embargo, "cuando supones una mujer lectora, el resultado es una experiencia de reclamo análogo" (Jonathan Culler 1982 44), puesto que los poemas maternales de Gabriela Mistral reflejan el arduo trabajo que significa maternar y la soledad de las madres al estar relegadas a la vida familiar

Duerme, duerme, dueño mío,

Sin zozobra, sin temor,

Aunque no se duerma mi alma,

Aunque no descanse yo

... 
El sueño mío que rompieron,

No lo supe dormir después,

Y cuando lloro todavía

Lloro mi Noche de Belén (1906).

Sin duda, Mistral expone el apego maternal que existe entre madres e hijas/hijos, pero, del mismo modo evidencia la carencia paternal y el abandono de éste en la labor de criar:

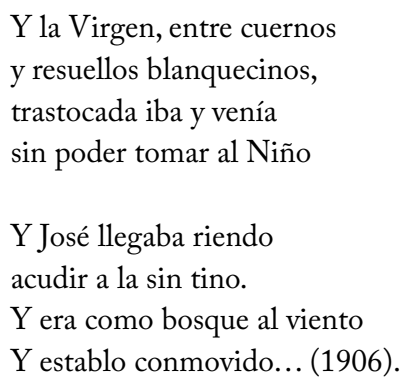

Ciertamente la lectura que se le ha dado a la obra de Mistral ha sido para ocultar aspectos relevantes de su vida como lo son su postura política a favor de las causas obreras e indígenas, su inherente feminismo y por qué no decirlo, su lesbianismo para resaltar y crear una imagen más sensible y amable preocupada por la infancia y las madres del mundo y así enorgullecerse del prestigioso del Nobel. De acuerdo a esto, cabe preguntar ¿Puede considerarse a Gabriela Mistral la madre de Chile cuando su contenido poético reafirma la existencia del dominio patriarcal en la labor de maternar?
Me quedo sola y no despierto
Al que está viendo lo que ve:
Las palomas, las codornices,
El agua rosa, el río miel... (1906).

Evidentemente el canon ratifica esto ya que convierten a Mistral en la madre del patriarcado despojando de ella su lado subversivo. Considerando lo último, afirmar que Mistral es la madre de Chile es negar su figura completa, su rebeldía, su transgresión, su feminismo, su lesbianismo; afirmar que Mistral es la madre de Chile es aceptar la literatura patriarcal que despoja a cuánta escritora y poeta mujer le quiera enfrentar. Como dice María Elena Wood (2016) "Es imposible entender la pasión de su poesía sin conocer las fuerzas internas que la movían", porque cuando no se saben las motivaciones, las emociones y los sentires, es fácil leer un poema donde la hablante lírica sea una madre y desde ahí crear una figura indiscutible de la imagen completa de Mistral. 
Para concluir, se ha demostrado que la figura de Gabriela Mistral es mucho más que la que se han inventado durante décadas de la profesora rural, la católica y la madre, sin negar la preocupación que siempre tuvo Gabriela por la infancia y por el cobijo que les dio a las madres y mujeres en general en su poesía. Ciertamente es aquella preocupación la que precede a su transgresión y había que reinventarla de alguna forma para no deslucir el primer Nobel que estaba teniendo Chile y así, de paso, mantener la estructura social, machista y patriarcal de la época. Sin embargo, a través de su obra Mistral sutil, pero, directamente arremete contra dicha estructura evidenciando las desigualdades e injusticias de género que el sistema patriarcal perpetuó [entre otros temas que toca la obra completa de Mistral]. En concreto, su poesía cobijó a mujeres, mujeres madres y niñas en un espacio donde pudieran ser soberanas de ellas mismas, afortunadas de tenerse y despreocupadas de obligaciones forzadas a cumplir, dicho espacio se expresa en la figura de la ronda donde convergen los entes femeninos y en una especie de aquelarre se complementan con la naturaleza

¡Haremos la ronda infinita!

¡La iremos al bosque a trenzar,

La haremos a los pies de los montes

Y en todas las playas del mar! (1906).

De acuerdo a la preocupación que tiene Mistral por cobijar , refugiar y proteger a las mujeres, y según las representaciones de género, se podría decir que, en este caso, Mistral sí actúa como madre, madre de las madres que busca proteger a mujeres violentadas por una sociedad injusta que las agrede física y emocionalmente y que desmerece la ardua y fatigante labor de maternar. Es así como Mistral reivindica y recupera la dignidad de la mujer confrontando al sistema patriarcal y a la sociedad que lo ampara descargando su inconformidad por medio de versos desobedientes a la estructura canónica de la literatura machista.

Finalizando, la figura transgresora de Gabriela Mistral es, para muchas, un símbolo de inspiración para llevar a cabo la lucha por el posicionamiento de la mujer en una sociedad que nos oprime y desvaloriza. Con su poesía no sólo consideró y dio suma importancia a la infancia, sino que a entes desprotegidos, denigrados y olvidados como lo son niñas, niños y mujeres por una sociedad patriarcal. Además, evidenció la violencia por parte de la figura de poder dentro de la estructura familiar y difundió la instrucción para las mujeres, sobre todo para las trabajadoras, ya que de esta forma se irían liberando del yugo patriarcal. 
Sin duda Gabriela Mistral es un personaje lésbico-femenino en la historia de Chile que, aún en la actualidad aparece su fantasma para guiarnos en una lucha que está lejos de terminar. Gabriela es una inspiración, un símbolo para no dejarnos avasallar por las injusticias del sistema machista-patriarcal que nos pretende exageradas, locas y delirantes... Locas y delirantes desde la perspectiva de Mistral. Gracias a su poesía podemos obtener la convicción de expresar lo que sentimos y actuar como queremos; gracias a su poesía dejamos atrás la violencia ejercida por la figura viril y comenzamos amarnos entre mujeres como la sociedad lo prohíbe; y gracias a la poesía de Mistral configuró la imagen de nosotras como Lindas, Libres y LocAs.

\section{REFERENCIAS}

Ana Pais. (8 de marzo 2016). "La prefieren loca que lesbiana': La deuda de

Chile con Gabriela Mistral, la latinoamericana que ganó el Premio Nobel de Literatura". En BBC Mundo Recuperado de https://www. bbc.com/mundo/noticias/2016/03/160307_cultura_chile_gabriela_mistral_lesbianismo_ap

Barrera, Decap, Quezada, Sepúlveda, . (2020). Obra reunida de Gabriela Mistral. Chile: Ediciones Biblioteca Nacional.

Culler, J. (1998). Sobre la deconstrucción: teoría y crítica después del estructuralismo. Madrid: Ediciones Cátedra.

DAydí-Tolson, S. (1992). "Manifestaciones de la locura femenina en la poesía de Gabriela Mistral”. En AIH Actas Irvine, (XI), 181-187

Gazarian, M. (2008). "Siempre buscó su Valle del Elqui”. En Patrimonio Cultural, (46), 6-7.

Mistral, G. (1906). Instrucción a la mujer La Voz del Elqui.

PÉrez Morales, M.I., Menéndez Martínez, M., \&Jacomino Ruiz, A. (2019).

"El papel de la mujer en la obra de Gabriela Mistral". En Revista Científica Cultura, Comunicación y Desarrollo, 4(1), 16-21. Recuperado de http://rccd.ucf.edu.cu/index.php/rccd

Piñones, J. (1998). "Sobre cómo se ha leído a Gabriela Mistral”. Revista Logos, (8), 131-130.

Ricardo Brodsky. (09 marzo 2017). “Gabriela Mistral y el Feminismo”. Chile.

Cooperativa Recuperado de https://opinion.cooperativa.cl/opinion/ cultura/gabriela-mistral-y-el-feminismo/2017-03-09/064955.html Richard, N. (1994, marzo 1). “'Tiene sexo la escritura?”. Debate Feminista,

9. https://doi.org/https://doi.org/10.22201/cieg.2594066xe.1994.9 .1755 . 